\title{
Assessing the quality of life of children with mental disorders using a computer-based self-reported generic instrument (KidIQoL)
}

\author{
-Quality of life of children with mental disorders
}

\author{
Melanie White-Koning ${ }^{1}$, Martine Gayral-Taminh ${ }^{2}$, Valérie Lauwers-Cancès ${ }^{3}$, Hélène Grandjean ${ }^{2}$, \\ Jean-Philippe Raynaud ${ }^{2,4}$
}

${ }^{1}$ EA3035, Institut Claudius Regaud, Toulouse, France;

${ }^{2}$ INSERM, UMR 1027, Université Paul Sabatier, Toulouse, France;

${ }^{3} \mathrm{CHU}$ de Toulouse, Department of Epidemiology and Public Health, Toulouse, France;

${ }^{4} \mathrm{CHU}$ de Toulouse, University Department of Child and Adolescent Psychiatry, Toulouse, France.

Email: raynaud.jph@chu-toulouse.fr

Received 5 March 2011; revised 12 April 2011; accepted 20 April 2011.

\begin{abstract}
OBJECTIVE: To assess the self-reported quality of life (Qol) of children with various mental disorders and compare the scores in this population with those in children without such problems. METHODS: Selfreported Qol was assessed using KidiQoL, a generic computer-based tool with 44 items exploring four domains (Physical and psychological health, Family life, School life and Social and physical environment). The study group consisted of 139 children (111 boys and 28 girls) aged between 6 and 12 years (mean age 9.1 years) referred to an outpatient mental health unit for mental disorders, 29 of whom completed the questionnaire about 2 weeks later in order to assess test-retest reliability. The comparison group consisted of 130 children from the general population, aged 6 to 12 years (mean age 9.0 years) and attending mainstream schools in the same geographical area. RESULTS: The test-retest reliability of the instrument was very good with an intraclass correlation coefficient of 0.97 for the total score and above 0.90 in all domains. No significant differences in domain and total scores were observed according to gender or developmental age. Children with developmental disorders or schizophrenia reported significantly lower QoL in the Health domain than children with other types of mental disorders. In all domains and for the total score, the children with mental disorders reported significantly lower QoL than the children from the general population; CONCLUSION: KidIQoL has been found suitable and psychometrically valid in children with mental disorders. Its use could help the
\end{abstract}

assessment and adaptation of psychiatric care.

Keywords: Quality of Life; Mental Disorder; Children

\section{INTRODUCTION}

In child and adolescent psychiatry, clinical assessment remains largely focused on cognitive abilities or symptoms such as signs of depression, anxiety, psychosis, learning difficulties or adaptation disorders. It is however obvious to professionals working with such children that other dimensions of their lives should be explored and yield important information concerning their difficulties and suffering.

The current emphasis on quality of life $(\mathrm{QoL})$ reflects this widely held view that traditional outcome measures, including survival or presence of disabilities or physical symptoms, do not capture the complete range of ways in which a patient may be affected by illness or treatment.

A difficulty in the assessment of QoL is the lack of consensus concerning its definition due to the breadth of the concept. In 1993, a working group within the World Health Organisation defined QoL as "an individual's perception of their position in life in the context of the cultural and values systems in which they live, and in relation to their goals, expectations, standards and concerns" [24]. QoL can be seen as a multidimensional construct encompassing several core domains, generally identified as material conditions, physical status and functional abilities, social interactions and emotional well-being.

While QoL research in adults has progressed substantially in the past 25 years, QoL measurement in children 
is still relatively new. However, it has received much greater attention in the past decade $[4,6,7,10]$.

A literature review published in 1995 found that child QoL was assessed by proxies in $90 \%$ of studies [4]. In 1993, the World Health Organisation (WHO) and the International Association for Child and Adolescent Psychiatry and Allied Professions (IACAPAP) jointly recommended that measures of QoL in children use subjective self-reporting wherever possible [23]. There are however developmental issues to be taken into consideration regarding children's self-reports of QoL. The quality of children's reports is highly dependent on their expressive and receptive language abilities, which vary according to the child's age and level of cognitive development. Furthermore, most QoL measures require the respondent to reply based on experiences during a specific time period (e.g. "in the past week" or "in the past month"). The ability of a child to respond to a time frame demand will depend on his/her memory and perception of time which again vary according to his/her level of cognitive development. Also, compared to adults or adolescents, children have fewer experiences on which to base their interpretation of events.

Hence it is essential that child QoL instruments be appropriately adapted to use with children. Questionnaire length, simplicity and attractiveness of the layout, comprehensibility of instructions and the length and wording of individual items all contribute to improving the clarity of paediatric QoL instruments. Children also need to be given sufficient time to complete the questionnaire. Recent research has shown that children are able to self-report on their well-being and functioning reliably if the questionnaire is appropriate to their age and cognitive level [11,15,17-19]. Children as young as 5 years have been found capable of answering questions about their QoL [13]. Consequently, an increasing number of child QoL studies have made efforts to obtain the children's own perspective $[6,10,14]$.

A problematic issue in the assessment of child QoL is the lack of measures based on children's own perspectives as to what constitutes a life of quality. Little is known about the relative importance that children attach to different life states. However, it is obvious that children do not share the same interests, life values and expectations as adults. Despite this, the vast majority of instruments used to assess children's QoL are largely based on (adult) researchers conceptualisations of QoL and some are even adaptations of instruments conceived for assessing QoL in adults $[4,10]$. In recent studies, a few researchers have obtained children's views on the important aspects of their life and used them to develop QoL instruments that would be relevant to children $[8,9$, 20,22].
Until now most studies of child QoL have involved healthy children or children with physical diseases. Very few studies have examined the QoL of children with mental disorders [1-3,5,16,21]. Furthermore most of the latter studies used parent or professional proxy-reports of child QoL. Our team was determined to obtain selfreports of QoL from children with mental disorders. However the aim was also to measure these children's QoL in the same way and according to the same standards as for children from the general population, leading us to prefer generic instruments over specific ones. A self-reported computer-based generic tool, KidiQoL has been developed by a team of researchers including child psychiatrists and methodologists. It is short and easy to administer and has been validated in children from the general population [12]. This paper aims to examine the psychometric properties of this instrument in a population of children with various mental disorders, determine whether it is suitable for use in this population and compare the scores in this population with those in children without such problems.

\section{METHODS}

\subsection{Population}

The sample consisted of 139 children (111 boys (80\%) and 28 girls) aged between 6 and 12 years (mean age 9.1 years) and referred to an outpatient mental health unit for the following conditions: Disorders of psychological development or Schizophrenia, schizotypal and delusional disorders (ICD F80-F89, $\mathrm{n}=55$, ICD F20-F29, $\mathrm{n}=$ 8), (Total, $\mathrm{n}=63,46 \%$ ), Behavioural and emotional disorders (ICD F90-F98) $(\mathrm{n}=31,22 \%)$, Neurotic, stressrelated and somatoform disorders (ICD F40-F48) ( $\mathrm{n}=$ $28,20 \%)$ and mood disorders (ICD F30-F39) $(\mathrm{n}=17$, $12 \%)$. Most children $(\mathrm{n}=84,60 \%)$ had learning difficulties yielding a lower developmental age than their chronological age: 44 children $(32 \%)$ had a developmental delay of 2 years or more (The developmental age was assessed with WPPSI-III and WISC-IV). The mean developmental age in the population was 7.9 years. Half of the children $(n=69,50 \%)$ went to mainstream school, $36 \%(\mathrm{n}=50)$ had schooling within the mental health care unit, while the remaining children $(\mathrm{n}=17,12 \%)$ were in special classes within mainstream schools. Finally, three children did not have any form of schooling. Of the 139 children, 29 completed the questionnaire a second time (about 2 weeks later) in order to assess test-retest reliability.

The comparison group consisted of 130 children from the general population, aged 6 to 12 years (mean age 9.0 years), attending mainstream schools and living in the same geographical area as the patient group. 


\subsection{Instrument}

The KidIQoL is a generic self-reported computer-based instrument for the assessment of quality of life in children aged 6 to 12 years. The measure includes 44 items covering 4 domains of quality of life: Physical and psychological health (13 items), Family life (9 items), School life (9 items) and Social and physical environment (13 items). A subscale score can be derived for each of these four domains as well as a total scale score summarising the whole instrument. KidIQoL is completed by the children themselves using a computer. The child first has to enter his/her gender and age. Each item is then presented as a sentence written out on the computer screen with a gender-sensitive illustration depicting the given situation (Figures $\mathbf{1}$ and 2). The child then has to click on one of 5 boxes representing the 5 Likertscale responses ranging either from "entirely agree" to "entirely disagree" or from "always" to "never", depending on the type of question. The questionnaire takes around 20 minutes for a child to complete. Each question is coded 1 to 5 , with higher scores representing better QoL. Domain scores are constructed by taking the mean of the item scores of the domain and linearly transforming it into a score on a scale from 0 to 100 . For the domains including 9 items (respectively 13 items), if there are less than or equal to 2 (respectively 3 ) missing values, these are replaced by the mean of the remaining items, otherwise the domain score is considered missing. The total scale score is the mean of all 44 items and is considered missing if one or more domain scores are missing.

\subsection{Statistical Analyses}

The internal consistency of each domain and of the entire scale was determined using Cronbach's $\alpha$ coefficients. A confirmatory factor analysis was carried out to determine whether the factor structure in children with mental disorders corresponded to the four domains identified by the authors' initial validation on ordinary children [12]. Test-retest reliability was examined using one-way analysis of variance and intraclass correlation coefficients (ICC). The Spearman correlation of each item with its own domain score (omitting that item) and with the other domain scores was computed in order to check the item-discriminant validity of the instrument.

Mann-Whitney and Kruskal-Wallis non-parametric tests were used to test whether the total and domain scores varied according to gender, chronological and developmental age, type of mental health problem and type of schooling. The total and domain scores of the children with mental disorders and those from the general population were also compared using Mann-Whitney's test.

\section{RESULTS}

The face validity of KidIQoL was good. Indeed the instrument was very favourably perceived both by the clinicians and by the children themselves. Most children were very quick to understand and use the questionnaire and particularly appreciated its computerised format. They seemed to find it relevant to them and enjoyed being asked about themselves. The children often asked to do the questionnaire again during subsequent therapy sessions.

Internal consistency as estimated by Cronbach's $\alpha$ was very good for the total scores, good for the Health and School domains and adequate for the Family and Environment domains (Table 1). Furthermore, item-discriminant validity was satisfactory with the majority of items correlating more strongly with their own domain than with the other domains (ranges given in Table 1). The test-retest reliability of the instrument was very good with ICCs above 0.90 in all domains and ICC $=0.97$ for the total score. The confirmatory factor analysis showed that the factor structure in our population of children with mental disorders corresponded broadly with the domains identified by the authors of the instrument.

We found no significant difference in domain and total scores according to gender or developmental age. Children with developmental disorders or schizophrenia reported significantly lower QoL in the Health domain than children with other types of mental disorders (Table 2). However, in the other domain scores and the total score there were no significant differences according to type of mental problem. There were significant differences in scores according to type of schooling in all domains except for the Family domain (Table 3). In the School and Environment domains, children attending special classes in mainstream schools reported signifycantly higher QoL than children in mainstream schools or those schooled in the mental health unit. While in the Health domain, children schooled in the mental health unit reported significantly lower QoL than those in mainstream schools or those in special classes in mainstream schools. In all domains and for the total score, the children with mental disorders reported significantly lower QoL than the children from the general population.

\section{DISCUSSION}

The aim of this study was to examine the psychometric properties of KidIQoL, a self-reported QoL instrument, in children with various mental disorders and to determine its suitability for use in such children.

In 1993, the WHO and the International Association for Child and Adolescent Psychiatry and Allied Profes- 
Table 1. Median, Means, Cronbach's $\alpha$ and correlations for domain and total scores.

\begin{tabular}{|c|c|c|c|c|c|c|c|c|}
\hline & $\mathbf{N}$ & Median & Mean & $S D$ & Cronbach's $\alpha$ & $\begin{array}{l}\text { Correlations } \\
\text { of items with } \\
\text { own domain }\end{array}$ & $\begin{array}{l}\text { Correlations of } \\
\text { items with other } \\
\text { domains }\end{array}$ & $\begin{array}{l}\text { ICC* for } \\
\text { test-retest }\end{array}$ \\
\hline School life & 136 & 66.7 & 65.0 & 13.9 & 0.76 & $0.25-0.74$ & $0.003-0.43$ & 0.95 \\
\hline Family life & 132 & 73.3 & 72.4 & 9.9 & 0.55 & $0.03-0.52$ & $0.002-0.53$ & 0.96 \\
\hline $\begin{array}{l}\text { Physical and psychological } \\
\text { health }\end{array}$ & 139 & 52.3 & 54.5 & 12.0 & 0.79 & $0.25-0.60$ & $0.03-0.40$ & 0.90 \\
\hline $\begin{array}{l}\text { Social and physical } \\
\text { environment }\end{array}$ & 139 & 75.4 & 74.8 & 8.0 & 0.56 & $0.05-0.53$ & $0.003-0.41$ & 0.95 \\
\hline Total score & 130 & 64.8 & 66.2 & 7.6 & 0.82 & $0.03-0.54$ & & 0.97 \\
\hline
\end{tabular}

*ICC = Intraclass Correlation Coefficient.

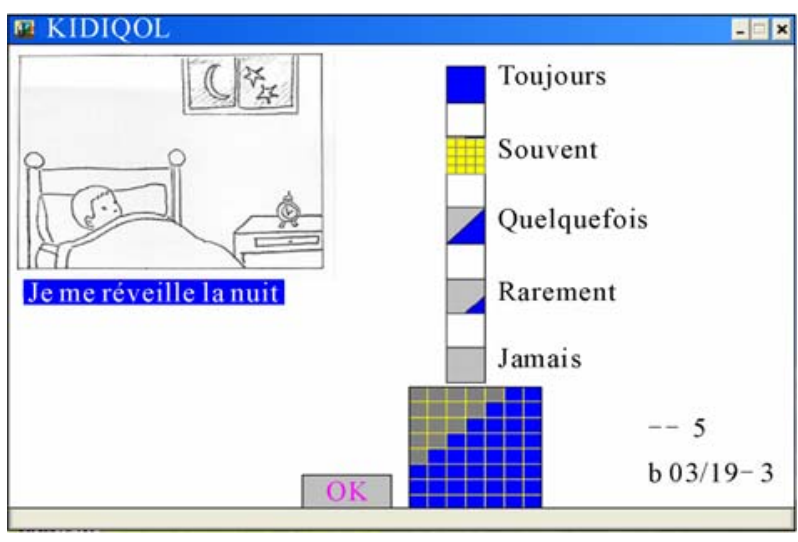

Figure 1. Boy item example and «frequency» Lickert-type response scale. Item: "I wake up at night"; Lickert-type response scale: "Always, Often, Sometimes, Rarely, Never".

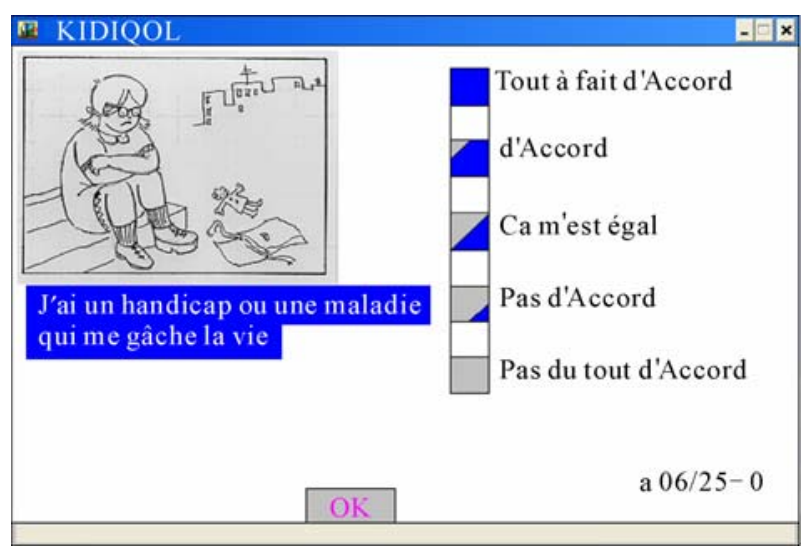

Figure 2. Girl item example and «satisfaction» response scale. Item : "I have a disability or illness that makes my life unpleasant"; Response scale: "I entirely agree, I agree, I do not care, I disagree, I entirely disagree".

sions (IACAPAP) jointly recommended that measures of QoL in children use subjective self-reporting wherever possible [23]. Despite this, few studies in the literature have examined the QoL of children with mental disor- ders, exceptions being Clark and Kirisci [5] who included self-reports of adolescents and Bastiaansen et al. [1] who compared child and parent reports of QoL in a population of children referred for psychiatric problems. The KidIQoL is a generic tool which has been used in children from the general population but which we also found clinically relevant for assessing the QoL of children with mental disorders. Compared to other tools it has the additional strengths of being both illustrated and computerised making it attractive and simple for children.

KidIQoL had good face validity; it was perceived as relevant and enjoyable by children with various mental disorders. The gender-appropriate pictures which are used to illustrate each question are an essential asset, especially for children with mental disorders, many of whom are not fluent readers or writers and have problems understanding abstract concepts. The instrument is easy to use in everyday clinical practice and its computerised format means the data are automatically recorded, which avoids data entry and coding errors.

Furthermore, we found that the psychometric properties of the KidIQoL were satisfactory, with good internal consistency and satisfactory item-discriminant validity. The test-retest reliability of the questionnaire was very good. The factor structure of the questionnaire in children with mental disorders was found to correspond to the four-domain structure shown in ordinary children. Finally, the ability of the instrument to discriminate between different groups was good, since we found that in all four domains and overall, children with mental health disorders reported lower QoL than children from the general population. These results concur with those reported by Sawyer et al. [21] and Bastiaansen et al. [1] who found that children with psychiatric disorders had lower overall QoL than children with no disorder.

We found that there was no significant difference in median Total QoL scores or in the domain scores according to the type of mental disorder, except for the 
Table 2. Median scores according to type of mental disorder (ICD 10).

\begin{tabular}{|c|c|c|c|c|c|c|c|c|c|}
\hline & \multicolumn{2}{|c|}{$\begin{array}{c}\text { Developmental } \\
\text { disorders \& } \\
\text { schizophrenia } \\
\text { (F80-89 \& F20-29) } \\
\quad(n=63)\end{array}$} & \multicolumn{2}{|c|}{$\begin{array}{c}\text { Behavioural and } \\
\text { emotional disorders } \\
(\text { F90-F98) } \\
(\mathbf{n}=\mathbf{3 1})\end{array}$} & \multicolumn{2}{|c|}{$\begin{array}{l}\text { Neurotic disorders } \\
(\text { F40-F48) } \\
(\mathbf{n}=\mathbf{2 8})\end{array}$} & \multicolumn{2}{|c|}{$\begin{array}{l}\text { Mood disorders } \\
\quad(\mathbf{F 3 0 - 3 9 )} \\
(\mathbf{n}=\mathbf{1 7})\end{array}$} & \multirow[t]{2}{*}{$\begin{array}{c}\text { Kruskal-Wallis } \\
\text { test }(p)\end{array}$} \\
\hline & Median & $I Q R^{*}$ & Median & $I Q R^{*}$ & Median & $I Q R^{*}$ & Median & $I Q R^{*}$ & \\
\hline School life & 68.9 & $60.0-73.3$ & 66.7 & $52.5-75.6$ & 53.3 & $46.7-68.9$ & 68.9 & $60.0-77.8$ & 0.11 \\
\hline Family life & 71.1 & $65.0-77.5$ & 74.2 & $66.3-80.0$ & 75.6 & $66.7-80.0$ & 72.9 & $68.9-78.9$ & 0.44 \\
\hline $\begin{array}{c}\text { Physical and } \\
\text { psychological health }\end{array}$ & 49.2 & $43.1-58.5$ & 55.4 & $47.7-66.2$ & 57.7 & $46.2-67.7$ & 56.9 & $49.2-66.2$ & 0.02 \\
\hline $\begin{array}{c}\text { Social and physical } \\
\text { environment }\end{array}$ & 72.3 & $69.2-76.9$ & 73.8 & $69.2-78.5$ & 76.9 & $70.0-80.0$ & 76.9 & $70.8-83.1$ & 0.25 \\
\hline Total score & 64.1 & $60.9-68.2$ & 65.2 & 61.9-72.0 & 64.1 & $60.9-72.3$ & 68.2 & 61.6-73.6 & 0.52 \\
\hline
\end{tabular}

*IQR = Inter Quartile Range.

Table 3. Median scores according to type of schooling.

\begin{tabular}{|c|c|c|c|c|c|c|c|}
\hline & \multicolumn{2}{|c|}{$\begin{array}{l}\text { Mainstream school } \\
\qquad(n=69)\end{array}$} & \multicolumn{2}{|c|}{$\begin{array}{c}\text { Special class in } \\
\text { mainstream school } \\
(n=17)\end{array}$} & \multicolumn{2}{|c|}{$\begin{array}{l}\text { Schooling in mental } \\
\text { health care unit } \\
(\mathrm{n}=\mathbf{5 0})\end{array}$} & \multirow[t]{2}{*}{$\begin{array}{c}\text { Kruskal-Wallis } \\
\text { test }(p)\end{array}$} \\
\hline & Median & $I Q R^{*}$ & Median & $I Q R^{*}$ & Median & $I Q R^{*}$ & \\
\hline School life & 66.7 & $51.1-77.8$ & 73.3 & $71.1-75.6$ & 66.7 & $53.3-71.1$ & $\mathbf{0 . 0 3}$ \\
\hline Family life & 73.3 & $67.5-80.0$ & 75.6 & $72.5-84.4$ & 71.1 & $62.2-77.8$ & 0.08 \\
\hline Physical and psychological health & 56.9 & $49.2-66.2$ & 56.9 & $49.2-61.5$ & 47.7 & $41.5-53.8$ & 0.0002 \\
\hline Social and physical environment & 75.4 & $69.2-81.5$ & 76.9 & $75.4-83.1$ & 73.1 & $69.2-76.9$ & 0.007 \\
\hline Total score & 66.3 & 61.4-72.7 & 70.9 & $66.2-74.1$ & 62.7 & $60.5-65.9$ & 0.0005 \\
\hline
\end{tabular}

*IQR $=$ Inter Quartile Range.

Physical and psychological health domain, where children with Developmental disorders or schizophrenia had lower QoL than children with other disorders. Similarly, Bastiaansen et al. [1] found no significant differences in Total or domain PedsQL scores between diagnostic categories, though in the Psychosocial health domain children with Pervasive developmental disorders and those with Mood disorders self-reported lower QoL than those with other types of disorders.

Interestingly we found significant differences according to type of schooling in the Total score and all domain scores except Family life. Children who were schooled in mental health care units reported significantly lower QoL in the Health and Environment domains than children who were individually or collectively integrated in main-stream schools, while those in special classes in main-stream schools (collective integration) reported significantly higher QoL than the other two groups in the School life domain and Total QoL score. This finding sheds an interesting light on the current debate concerning the best policy to adopt for the schooling of children with special needs; however it deserves more thorough exploration in future research projects.
An important component of the psychiatric care of children suffering from mental disorders is to enable them to see themselves as individuals with a personality and opinions, and the ability and duty to make their own choices. Thus, an instrument of self-reported QoL such as the KidIQoL is a useful starting point in clinical practice to encourage children to express their feelings concerning their well-being and overall satisfaction with life. As the questions cover many different aspects of daily life, clinicians will get a better idea of the child's feelings in specific areas and be able to adapt their programmes of care to the child's development and progress in order to help him/her to gain autonomy and a fulfiling place in society.

Another advantage of the routine use of the KidIQoL is the possibility of obtaining quantitative assessments of children's subjective QoL over time. This can be of particular importance when following a child's progress in terms of their acquisition of new cognitive or social abilities over a period of time and as an indicator of the success of certain changes in the child's environment or type of schooling for example. 


\section{CONCLUSION}

There is a dearth of research on the QoL of children with mental disorders. The KidIQoL is a computer-based illustrated generic instrument of self-reported QoL for children aged 6 to 12 years which has been found suitable and psychometrically valid in children with mental disorders. Its use in everyday clinical settings has proved useful and should be encouraged as it is likely to help with the assessment and adaptation of psychiatric care. The authors declare no conflict of interest.

\section{REFERENCES}

[1] Bastiaansen, D., Koot, H.M., Bongers, I.L., Varni, J.W. and Verhulst, F.C. (2004) Measuring quality of life in children referred for psychiatric problems: Psychometric properties of the PedsQL 4.0 generic core scales. Quality of Life Research, 13, 489-495. doi:10.1023/B:QURE.0000018483.01526.ab

[2] Bastiaansen, D., Koot, H.M. and Ferdinand, R.F. (2005) Determinants of quality of life in children with psychiatric disorders. Quality of Life Research, 14, 1599-1612. doi:10.1007/s11136-004-7711-2

[3] Bastiaansen, D., Koot, H.M., Ferdinand, R.F. and Verhulst, F.C. (2004) Quality of life in children with psychiatric disorders: Self-, parent, and clinician report. Journal of the American Academy of Child and Adolescent Psychiarity, 43, 221-230.

doi:10.1097/00004583-200402000-00019

[4] Bullinger, M. and Ravens-Sieberer, U. (1995) Health related quality of life assessment in children: A review of the literature. European Review of Applied Psychology, 45, 245-254.

[5] Clark. D. and Kirisci, L. (1996) Posttraumatic stress disorder, depression, alcohol use disorders and quality of life in adolescents. Anxiety, 2, 226-233.

doi:10.1002/(SICI)1522-7154(1996)2:5<226::AID-ANX $\mathrm{I} 4>3.0 . \mathrm{CO} ; 2-\mathrm{K}$

[6] Connolly, M.A. and Johnson, J.A. (1999) Measuring quality of life in paediatric patients. Pharmacoeconomics, 16, 605-625. doi:10.2165/00019053-199916060-00002

[7] De Civita, M., Regier, D., Alamgir, A.H., Anis, A.H., Fitzgerald, M.J. and Marra, C.A. (2005) Evaluating health-related quality-of-life studies in paediatric populations: Some conceptual, methodological and developmental considerations and recent applications. Pharmacoeconomics, 23, 659-685. doi:10.2165/00019053-200523070-00003

[8] Detmar, S.B., Bruil, J., Ravens-Sieberer, U., Gosch, A. and Bisegger, C. (2006) The use of focus groups in the development of the KIDSCREEN HRQL questionnaire. Quality of Life Research, 15, 1345-1353. doi:10.1007/s11136-006-0022-z

[9] Eiser, C., Havermans, T., Craft, A. and Kernahan, J. (1995) Development of a measure to assess the perceived illness experience after treatment for cancer. Archives of Disease in Childhood, 72, 302-307. doi:10.1136/adc.72.4.302

[10] Eiser, C. and Morse, R. (2001) Quality-of-life measures in chronic diseases of childhood. Health Technology Assessment, 5, 151-157.

[11] Feeny, D., Furlong, W., Boyle, M. and Torrance, G.W. (1995) Multi-attribute health status classification systems. Health utilities index. Pharmacoeconomics, 7, 490-502.

[12] Gayral-Taminh, M., Matsuda, T., Bourdet-Loubère, S., Lauwers-Cances, V., Raynaud, J. and Grandjean, H. (2005) Self-evaluation of the quality of life of children aged 6 to 12 years old: Construction and first steps in the validation of kidlQol, a generic computer-based tool. Sante Publique, 17, 167-177. doi:10.3917/spub.052.0167

[13] Glaser, A.W., Furlong, W., Walker, D.A., Fielding, K., Davies, K., Feeny, D.H. and Barr, R.D. (1999) Applicability of the Health Utilities Index to a population of childhood survivors of central nervous system tumours in the U.K. European Journal of Cancer, 35, 256-261. doi:10.1016/S0959-8049(98)00367-0

[14] Harding, L. (2001) Children's quality of life assessments: A review of generic and health related quality of life measures completed by children and adolescents. Clinical Psychology \& Psychotherapy, 8, 79-96. doi:10.1002/cpp. 275

[15] Juniper, E.F., Guyatt, G.H., Feeny, D.H., Griffith, L.E. and Ferrie, P.J. (1997) Minimum skills required by children to complete health-related quality of life instruments for asthma: Comparison of measurement properties. European Respiratory Journal, 10, 2285-2294. doi:10.1183/09031936.97.10102285

[16] Landgraf, J.M. and Abetz, L. (1996) Measuring health outcomes in pediatric populations: Issues in psychometrics and applications. In: B Spilker editor. Quality of life and pharmacoeconomics in clinical trials, Philadelphia (PA): Lip- pincott-Raven, 793-802.

[17] Raat, H., Bonsel, G.J., Essink-Bot, M.L., Landgraf, J.M. and Gemke, R.J. (2002) Reliability and validity of comprehensive health status measures in children: The Child Health Questionnaire in relation to the Health Utilities Index. Journal of Clinical Epidemiology, 55, 67-76. doi:10.1016/S0895-4356(01)00411-5

[18] Rebok, G., Riley, A., Forrest, C., Starfield, B., Green, B., Robertson, J. and Tambor, E. (2001) Elementary school -aged children's reports of their health: A cognitive interviewing study. Quality of Life Research, 10, 59-70. doi:10.1023/A:1016693417166

[19] Riley, A.W. (2004) Evidence that school-age children can self-report on their health. Ambulatory Pediatrics, 4, 371-376. doi:10.1367/A03-178R.1

[20] Ronen, G.M., Rosenbaum, P., Law, M. and Streiner, D.L. (1999) Health-related quality of life in childhood epilepsy: The results of children's participation in identifying the components. Developmental Medicine \& Child Neurology, 41, 554-549. doi:10.1017/S0012162299001176

[21] Sawyer, M., Whaites, L., Rey, J., Hazell, P., Graetz, B. and Baghurst, P. (2002) Health-related quality of life of children and adolescents with mental disorders. Journal of the American Academy of Child and Adolescent Psychiatry, 41, 530-537. doi:10.1097/00004583-200205000-00010

[22] Varni, J.W., Seid, M. and Rode, C.A. (1999) The PedsQL: Measurement model for the pediatric quality of life inventory. Medical Care, 37, 126-139. 
doi:10.1097/00005650-199902000-00003

[23] WHO (1993) Measurement of quality of life in children. Geneva: Division of Mental Health.

[24] WHOQOL (1993) Study protocol for the World Health
Organization project to develop a Quality of Life assessment instrument (WHOQOL). Quality of Life Research, 2, 153-159. doi:10.1007/BF00435734 